\title{
Numerical Modeling of the Fluid Flow in Continuous Casting Tundish with Different Control Devices
}

\author{
Zhu He, Kun Zhou, Shuang Liu, Wei Xiong, and Baokuan Li \\ Key Laboratory for Ferrous Metallurgy and Resources Utilization, Ministry of Education, \\ Wuhan University of Science and Technology, Wuhan 430081, China \\ Correspondence should be addressed to Zhu He; hezhu@wust.edu.cn
}

Received 23 August 2013; Accepted 16 September 2013

Academic Editor: Jianzhong Lin

Copyright (C) 2013 Zhu He et al. This is an open access article distributed under the Creative Commons Attribution License, which permits unrestricted use, distribution, and reproduction in any medium, provided the original work is properly cited.

\begin{abstract}
Numerical simulations were conducted to study the melt flow under the influence of control devices in a T-type two-strand bloom caster tundish via the open source Computational Fluid Dynamics software OpenFOAM. Three different cases were studied: a bare tundish, a tundish with two pairs of baffles, and a tundish equipped with a turbulence inhibitor and a pair of baffles. Turbulence inhibitor and baffles arrangement showed an improvement of the fluid flow characteristics, yielding lower values of dead volume and higher values of plug flow. With a turbulence inhibitor, the velocity of metal which flows directly toward the tundish floor is smaller and the turbulence kinetic energy of the melt top surface is lower than the other two arrangements.
\end{abstract}

\section{Introduction}

In the steel production route, continuous casting of liquid steel is the most important process. Basically, the tundish in the continuous casting is an intermediate vessel between the ladle and the mold to distribute and supply liquid steel to different molds at an approximately constant rate (Figure 1). In recent years, tundish has become more of a continuous reactor than merely an intermediate buffer to distribute and supply liquid steel with an approximately constant rate [1]. Various metallurgical operations, such as alloy trimming of steel, thermal and chemical homogenization, inclusion separation and floatation, are carried out in steel making tundishes. The time available for these operations is very short, and therefore, it is necessary to have a good understanding of fluid flow behavior in the tundish. Generally, two research methods, physical modeling and mathematical simulation [2-5], are used for the tundish configurations optimization and flow control devices, such as weirs, dams, baffles with inclined holes, and turbulence inhibitors (TI), have been widely used to increase residence times and plug flow volume of liquid steel [6-8].

Since detailed knowledge of the molten steel flow is a prerequisite to any effective flow-control optimization, significant efforts have been made by researchers to investigate fluid flow phenomena in tundish systems. Estimation of the various residence time distribution (RTD) parameters via the pulse tracer addition technique has been widely used to study the fluid flow patterns in tundish system [9-11]. In such studies, a tracer (e.g., dye, acid, or salt) is injected through the incoming water stream and its concentration at the exit is recorded as a function of time. The plot of the exit concentration against time is known as the RTD curve. The RTD of the fluid in a tundish is analyzed to characterize the flow which, normally, includes the determination of the extent of mixing (plug and mixed volumes) and the dead volume in the tundish. And it has been generally considered that the mathematical model is able to simulate RTD phenomena realistically [12-14].

In the present, work fluid flow in a $30 \mathrm{t}$ tundish with different flow control devices was investigated by mathematical models. In each case of study, flow characteristics, velocity patterns, RTD curves, and inclusion distribution were obtained. The objective in this work was to study the effects of the flow control devices on the fluid flow pattern and RTD curves in a T-type two-strand tundish of a bloom caster.

Figure 2 shows the physical dimensions of this problem. Design of the baffles and the turbulence inhibitor as well as the positions of the TI and baffles inside the tundish is also indicated in Figure 2. Three types of the tundishes were studied as follows: the bare tundish (Case I), a tundish with a pair of baffles (Case II), and a tundish with a TI 


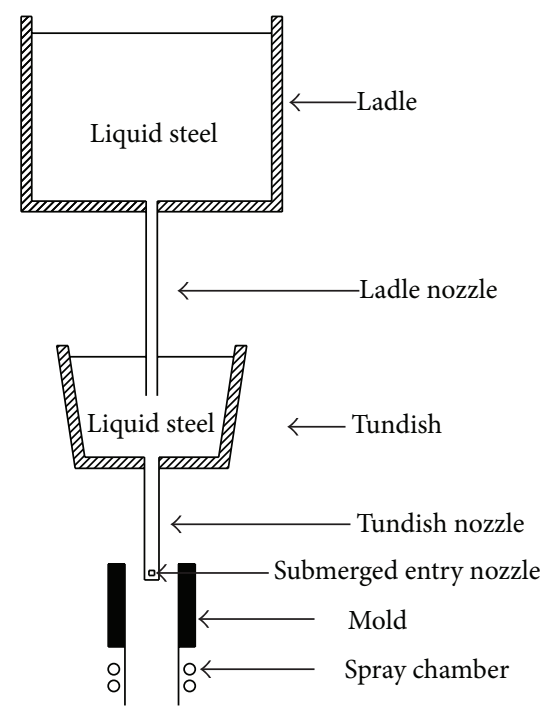

FIGURE 1: Schematic diagram of a continuous casting setup.
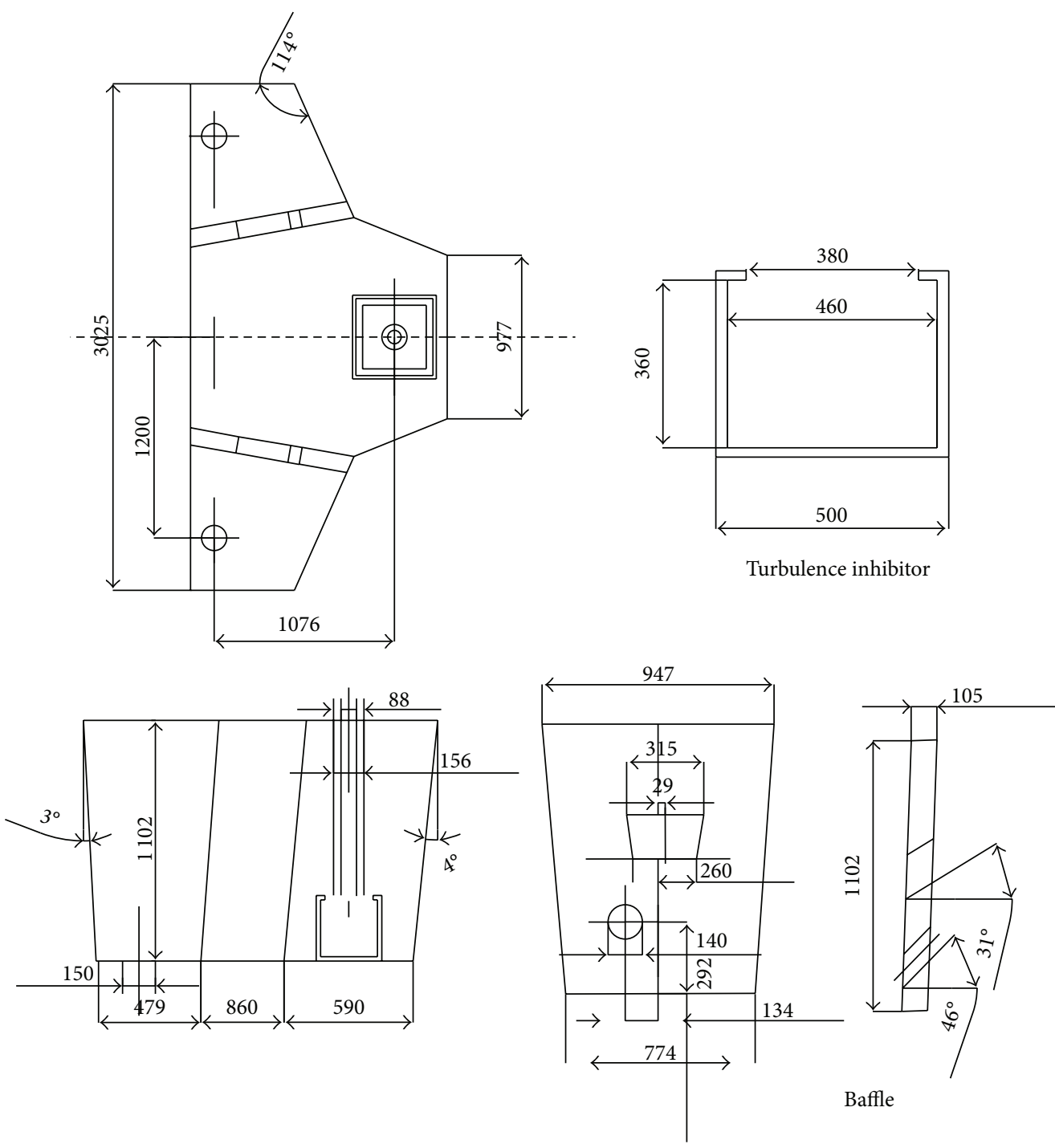

FIgURE 2: Physical dimensions of the tundish and the control devices. 
and a pair of baffles (Case III). The cross-section of slab is $1600 \mathrm{~mm} \times 200 \mathrm{~mm}$ and the casting speed is $1.2 \mathrm{~m} / \mathrm{min}$, so the corresponding flow rate is $0.768 \mathrm{~m}^{3} / \mathrm{min}$.

\section{Mathematic Formulation}

2.1. Fundamental Equations. The liquid steel flow in the continuous casting tundish can be considered to be threedimensional, Newtonian, and incompressible turbulence. A layer of slag at the top of liquid is neglected and the melt surface is assumed to be flat. The mathematical model, which is used to simulate the melt flow inside the tundish as well as the chemical mixing process of the tracer injected by a pulse in the incoming stream, was formulated based on the solution of the three-dimensional Navier-Stokes equations, the mass transfer equation, and two equations for the $k-\varepsilon$ model chosen to represent turbulent viscosity.

Continuity equation:

$$
\frac{\partial\left(\rho u_{j}\right)}{\partial x_{j}}=0
$$

Momentum equation:

$$
\rho u_{j} \frac{\partial u_{i}}{\partial x_{j}}=-\frac{\partial p}{\partial x_{i}}+\frac{\partial}{\partial x_{j}}\left(\mu_{\text {eff }}\left(\frac{\partial u_{i}}{\partial x_{j}}+\frac{\partial u_{j}}{\partial x_{i}}\right)\right)+\rho g_{i},
$$

where $u_{i, j}$ are the time-averaged fluid velocities in the $i$ th and $j$ th directions, respectively, $\rho$ is the liquid density, $p$ is the pressure in the fluid, $\mu_{\text {eff }}$ is the effective turbulent viscosity, $g_{i}$ is the gravitational acceleration in the $i$ th direction, $x_{i}$, $x_{j}$ are the spatial coordinates in the $i$ th and $j$ th directions, respectively, and $i, j$ denote the three directions in the global Cartesian coordinate system.

Effective viscosity $\mu_{\mathrm{eff}}$ is the sum of laminar viscosity $\mu$ and turbulent viscosity $\mu_{t}$ :

$$
\mu_{\mathrm{eff}}=\mu+\mu_{t}=\mu+\rho c_{\mu} \frac{k^{2}}{\varepsilon}
$$

The following equation describes the turbulent kinetic energy:

$$
\rho u_{j} \frac{\partial k}{\partial x_{j}}=\frac{\partial}{\partial x_{j}}\left(\frac{\mu_{\mathrm{eff}}}{\sigma_{k}} \times \frac{\partial k}{\partial x_{j}}\right)+G-\rho \varepsilon .
$$

The following equation describes the dissipation rate of turbulence energy:

$$
\rho u_{j} \frac{\partial \varepsilon}{\partial x_{j}}=\frac{\partial}{\partial x_{j}}\left(\frac{\mu_{\mathrm{eff}}}{\sigma_{\varepsilon}} \times \frac{\partial \varepsilon}{\partial x_{j}}\right)+\frac{\left(c_{1} G \varepsilon-c_{2} \rho \varepsilon^{2}\right)}{k},
$$

where $G$ is the generation of turbulence kinetic energy caused by the mean velocity gradients:

$$
G=\mu_{t} \frac{\partial u_{j}}{\partial x_{i}}\left(\frac{\partial u_{i}}{\partial x_{j}}+\frac{\partial u_{j}}{\partial x_{i}}\right)
$$

The values for the constants in this $k-\varepsilon$ model $c_{1}, c_{2}, c_{\mu}, \sigma_{k}$, and $\sigma_{\varepsilon}$ are $1.44,1.92,0.09,1.00$, and 1.30, respectively [15].
Mass transfer equation:

$$
\frac{\partial C}{\partial t}+u_{i} \frac{\partial C}{\partial x_{i}}=-D_{\mathrm{eff}} \frac{\partial}{\partial x_{j}}\left(\frac{\partial C}{\partial x_{j}}\right) .
$$

In the mass transfer equations, $C$ is the tracer concentration. $D_{\text {eff }}=D_{m}+D_{t}$ is the effective mass transfer diffusivity, which is the summation of molecular and turbulent diffusivities, respectively. The turbulent diffusivity $D_{t}$ is related to the turbulent viscosity $\mu_{t}$ by

$$
D_{t}=\frac{\mu_{t}}{\rho}
$$

which means that the turbulent Schmidt number is equal to one.

2.2. Boundary and Initial Conditions. Due to symmetry, only a half tundish from the symmetric central-longitudinal plane was chosen for this mathematical simulation. On the top surface of the bath and in symmetry planes, the fluxes of all variables were set equal to zero. No slip conditions were applied to all solid surfaces of the tundish including baffles, and interior walls of the tundish and standard wall functions were applied. The tundish exit is computationally treated as a plane, at which flow occurs at an ambient pressure. The vertical velocity profiles of the liquid steel at the inlet of the tundish were assumed to be uniform through the cross-sections and the other two velocity components were assumed to be zero. The values of $k$ and $\varepsilon$ at the inlet were calculated from the inlet average velocity through the following equations:

$$
\begin{aligned}
& U_{\text {in }}=\frac{Q}{A_{\text {nozzle }}}, \\
& k_{\text {in }}=0.01 U_{\text {in }}^{2}, \\
& \varepsilon_{\text {in }}=\frac{2 k_{\text {in }}^{2 / 3}}{D_{\text {nozzle }}} .
\end{aligned}
$$

The initial condition for (5) is that the tracer concentration is zero except in the ladle nozzle from the injection point to the nozzle tip.

2.3. Geometry and Numerical Methods. A control volumebased technique was used to convert the nonlinear governing equations to algebraic equations that can be solved numerically using the 3D mesh (Figure 3). A dense mesh was employed near the wall of the tundish. SIMPLE algorithm [16] was applied for the pressure-velocity coupling. A segregated and implicit solver was used to solve the governing equations and the second-order accuracy upwind differencing scheme was adopted to improve the accuracy of the solution. The open source Computational Fluid Dynamics software OpenFOAM [17] was used to compute the velocity and concentration fields. OpenFOAM is an open source code which is designed for continuum mechanics applications and has attracted much attention recently. It is an object oriented 


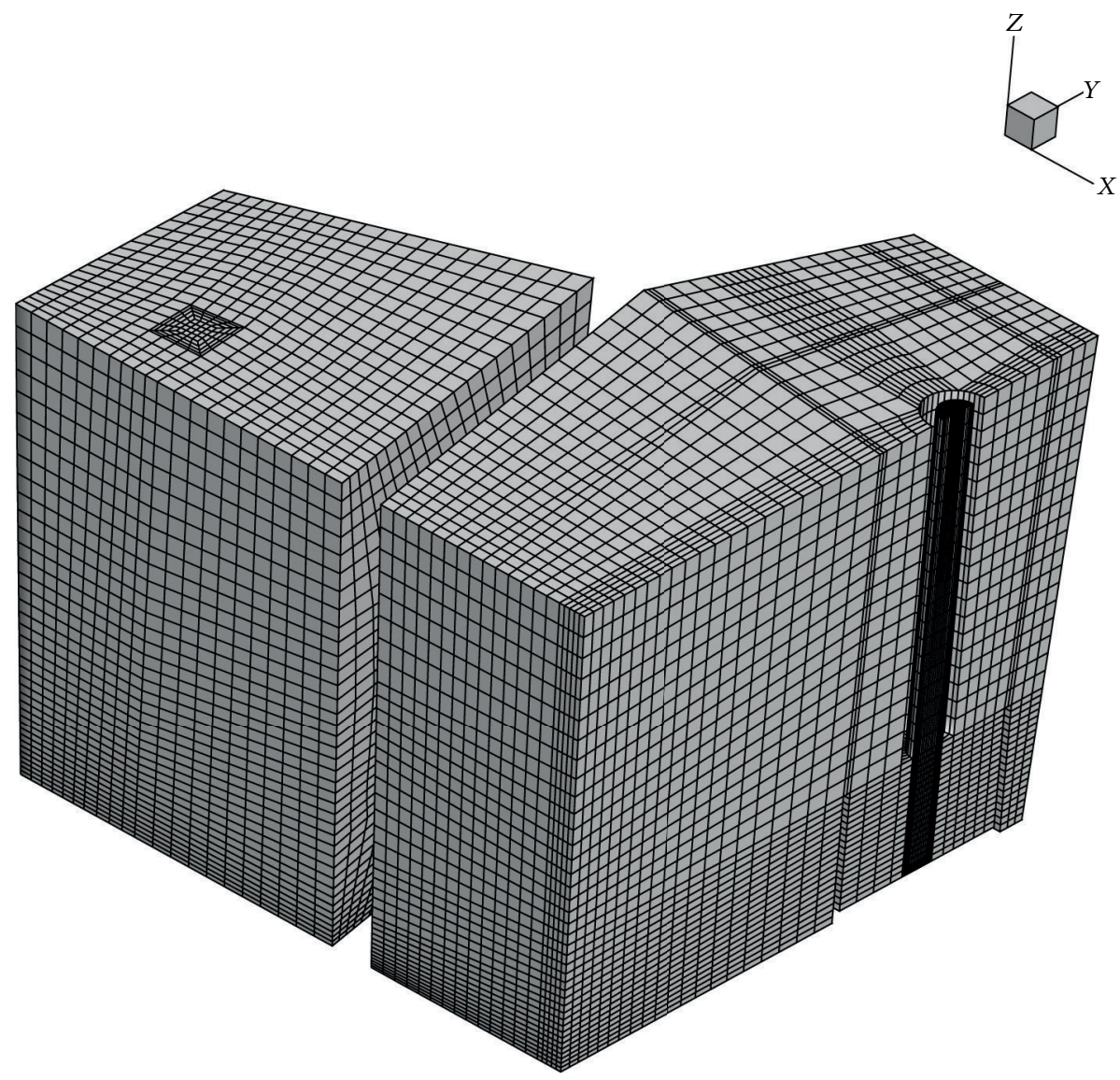

FIGURE 3: 3D computational mesh employed in the present model.

programming based toolbox which makes it sustainable in terms of reuse and development by users all around the world. OpenFOAM gives a flexible framework which combined almost all the required tools for solving CFD problem. Firstly, (1)-(4) were solved together with their boundary conditions until the steady state of the fluid flow was reached. Then the velocity field was employed to solve (7) for the tracer concentration under unsteady state conditions. Here, the tracer was treated as a passive scalar; that is, the presence of the tracer does not affect the melt flow. A criterion for convergence was set to be less than $10^{-5}$ on all variables and computations were carried out until the relative sum of residuals on all variables fell below the stipulated value.

\section{Results and Discussion}

3.1. Model Validation. In this section, the fluid flow model was validated against the experimental data [18] in the water model for a single inlet, single outlet tundish in which the tracer concentrations with time at the outlet were measured. The bath height was kept at $260 \mathrm{~mm}$ in the experiment and the same height was used for the model accordingly. Figure 4 shows the temporal variation of the tracer concentration (nondimensional) with nondimensional time and its comparison with the experiment. It can be seen that the overall characteristics of the RTD curve predicted by the present

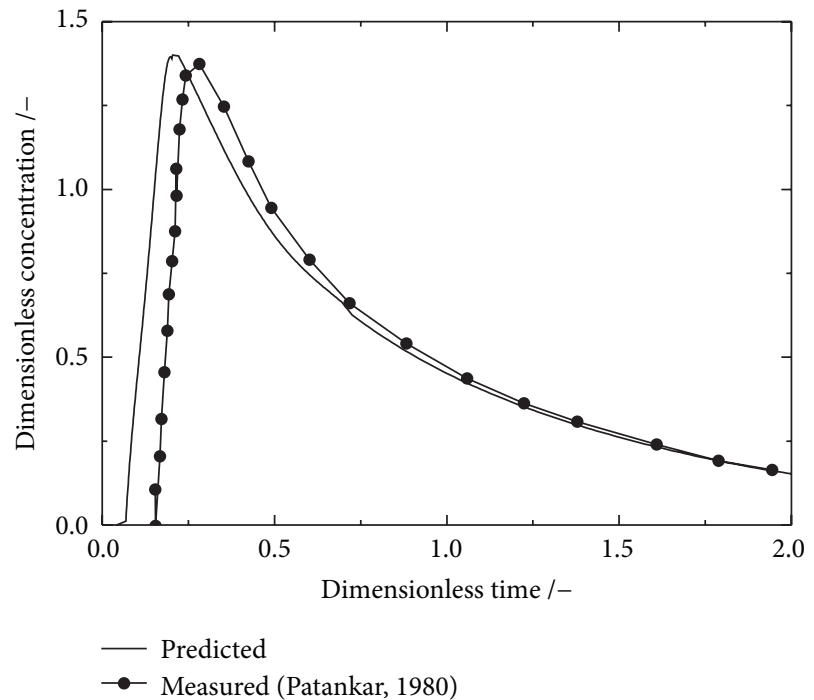

FIGURE 4: Comparison of the predicted and measured RTD curves.

mathematical model match quite well with the experimental data although some delays existed.

A typical grid independence test (i.e., $51 \times 58 \times 34$, $63 \times 79 \times 40$, and $76 \times 96 \times 48)$ of the present numerical calculation was evaluated in Figure 5 which shows the profiles 


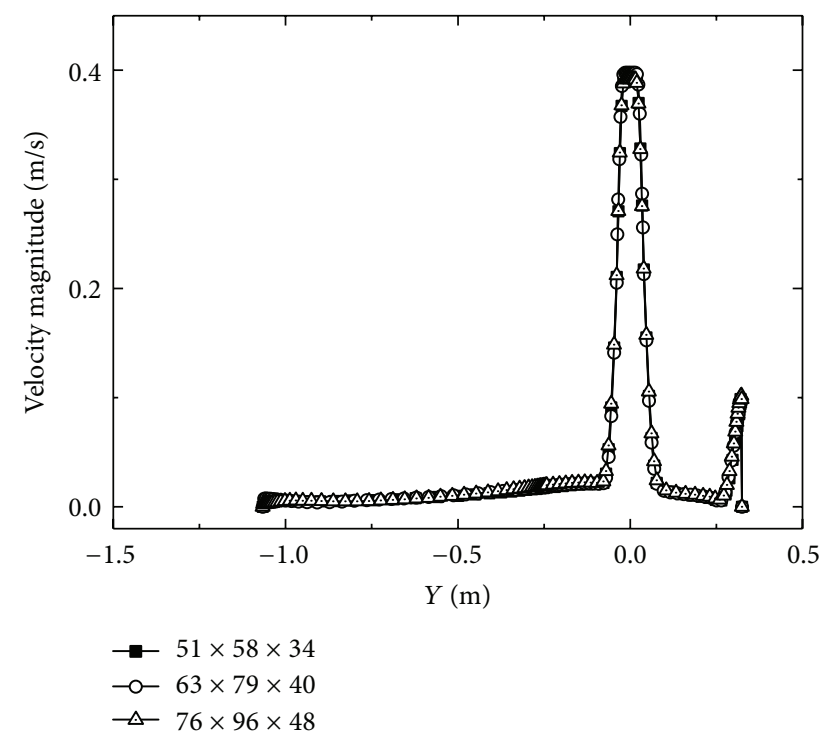

FIGURE 5: Grid independence check of solutions in a bare tundish.

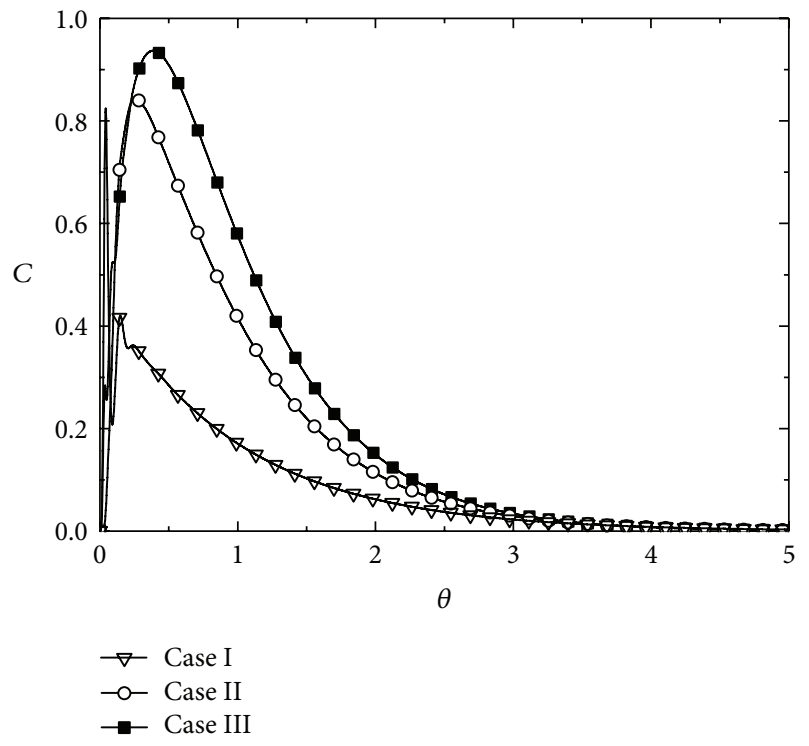

FIgURE 6: RTD curves for the three cases studied.

of the velocity at various transverse positions in the symmetry plane of the bare tundish $(x=0,-1.066 \leq y \leq 0.324$, $z=0.1)$. According to the results, the grid size schemes of $63 \times 79 \times 40$ and $76 \times 96 \times 48$ have almost the same velocity magnitude distribution, which demonstrates that the grid size scheme of $63 \times 79 \times 40$ is accurate enough for the present numerical calculation.

3.2. Effects of the Control Devices on the RTD Curve. Figure 6 shows the comparison of the RTD for the three studied cases. The curve for Case I is characterized by two peak values of concentrations, one soon after the tracer injection and then the second. After then, the tracer concentration decreases continuously with time. This is because a portion of the liquid moves on the horizontal plane straight towards the exit [19]. The existence of the two peak values of concentration may

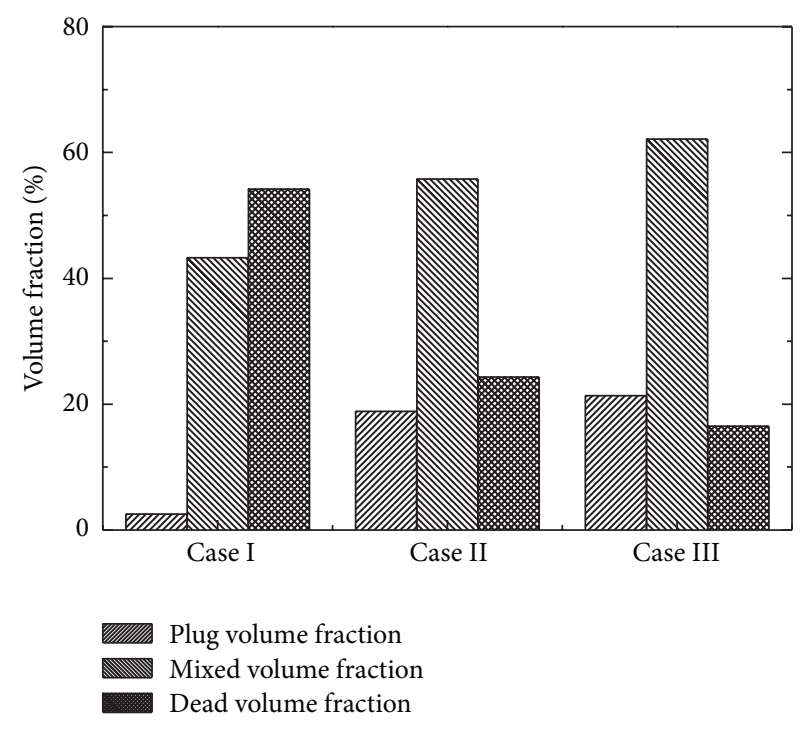

FIgURE 7: Volume fraction of flow for the studied cases.

TABLE 1: RTD parameters in the tundish system.

\begin{tabular}{lccc}
\hline Tundish configuration & $t_{\min }(\mathrm{s})$ & $t_{\max }(\mathrm{s})$ & $t_{\mathrm{av}}(\mathrm{s})$ \\
\hline Case I & 17 & 28 & 288 \\
Case II & 65 & 118.8 & 259.6 \\
Case III & 70 & 164.2 & 325.5 \\
\hline
\end{tabular}

suggest that the flow field in the tundish is short circuited and that is undesirable in tundish fluid system. Thus the bare tundish is associated with considerable short-circuiting and large dead volumes, which are potentially detrimental to the floatation of nonmetallic inclusions. As seen from Figure 6, the RTD parameters in Case II and III are improved considerably and only one peak value appeared.

From the RTD curves, minimum residence time, $t_{\text {min }}$, peak concentration time, $t_{\mathrm{max}}$, and mean residence time, $t_{\mathrm{av}}$, can be obtained for each case. Considering that there is fluid exchange between the fluids in the dead zone and in the active zone, the flow model proposed by Sahai and Emi [20] was employed in this work to calculate dead volume fraction, the fractions of plug flow and well-mixed volumes.

Table 1 shows a summary of the flow characteristics in the tundish with different flow control devices. Each volume fraction of flow for the studied cases is shown in Figure 7. It can be seen that the associated dead volume is significantly high for the bare tundish. The application of baffles brings down the dead volume from $54 \%$ to $24 \%$ and it is further decreased to $16 \%$ with the TI+baffle configuration as is clearly mentioned in Table 1 . The better mixing in the tundish occurs corresponding to higher well-mixed along with lower dead volume and therefore it is also expected for better temperature homogenization. At the same time, higher plug volume with minimum dead region shows the better inclusion removal in the tundish.

3.3. Analysis of Velocity Fields. Figure 8 shows the predicted flow fields in one half of the two-strand bare tundish system 

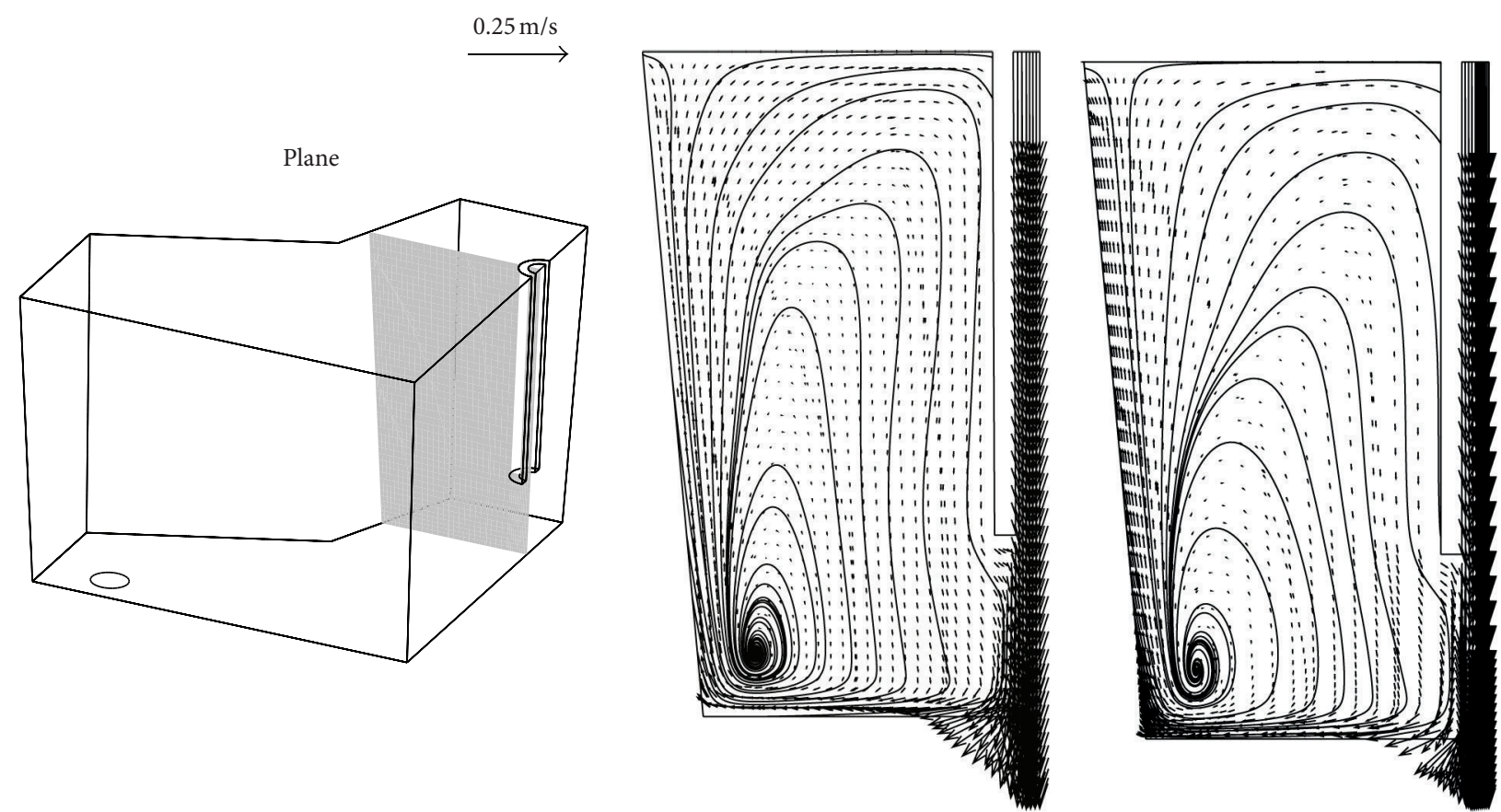

(a)

(b)

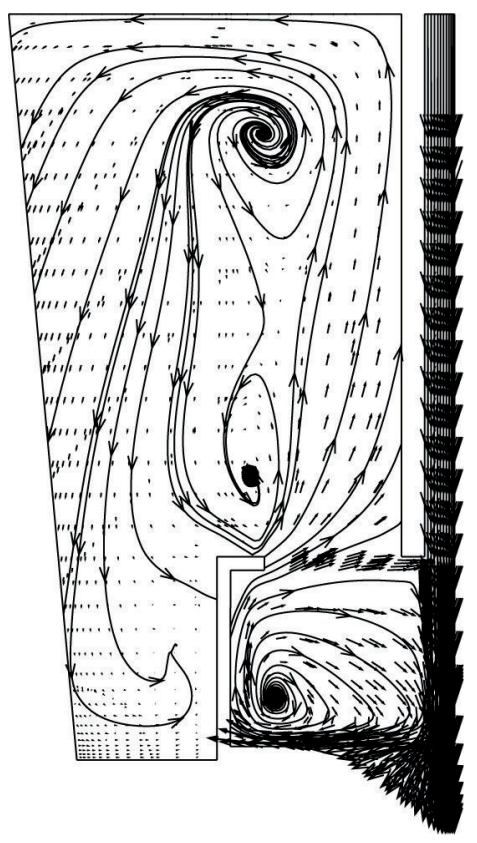

(c)

FIGURE 8: Predicted metal flow field in tundish for all cases: (a) Case I, (b) Case II, and (c) Case III.

which represent the velocity fields in $Y Z$ plane (central longitudinal vertical plane) at $X=0$ (inlet stream). Highly turbulent flow can be clearly seen near the inlet region of the tundish. The incoming jet hits the tundish bottom with very high velocity, which is evidently shown in Figure 8(a). After striking the tundish bottom, the melt partly moves up along the tundish side walls to the free surface, partly moving downstream to the exit and the rest recirculating back toward the incoming jet. The strong velocity fields thus created are responsible for reversal of flow towards the inlet stream and generated clockwise recirculatory flow. The impact of the melt flow on the walls will result in high refractory wear in the entry zone and the wall refractory wear will increase the exogenous inclusion count of the steel supplied to the molds. Figure 8(b) shows the flow fields for Case II, which is very similar to Case I. With the aid of the TI in Case III, though the recirculating flow remains, it is directed toward the tundish floor and the turbulent flow with smaller velocity vectors is well controlled, as shown in Figure 8(c). At the same time, due to the high turbulence level in the TI area, it would be the best 


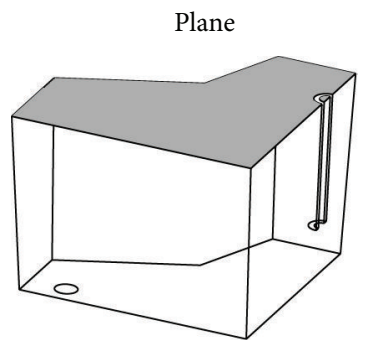

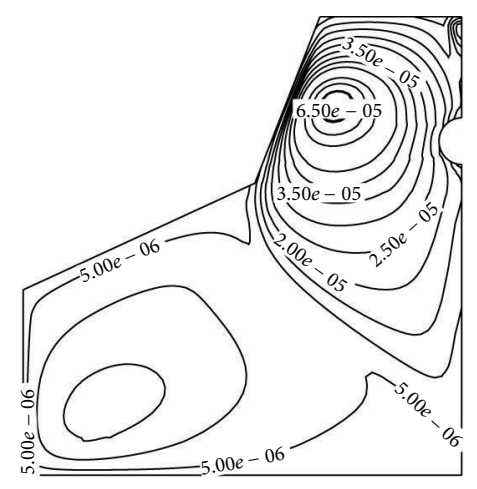

(a)

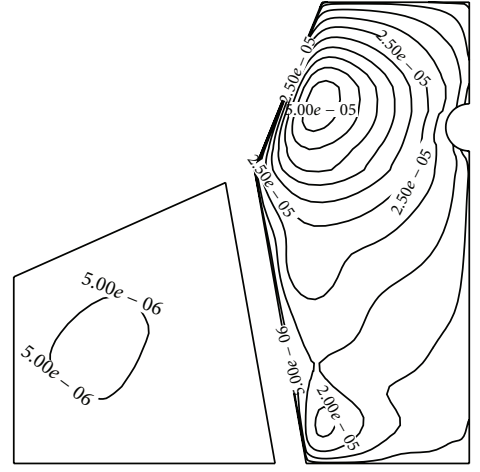

(b)

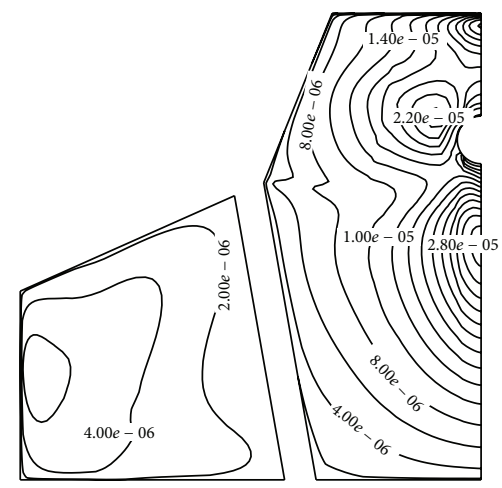

(c)

FIgURE 9: Predicted turbulent kinetic energy field in tundish for all cases: (a) Case I, (b) Case II, and (c) Case III.

region to make any alloy additions in the tundish. And along with the higher convective and diffusive mixing in this region, the alloy will get uniformly distributed in the rest of the tundish, which results in homogeneity during the casting.

Figure 9(a) through Figure 9(c) shows the predicted turbulence kinetic energy contours along the top surface of one half of the tundish for Cases I, II, and III, respectively. The high turbulence kinetic energy is associated with the liquid steel top surface instability and the entrainment of the slag. As seen from Figure 9(a), the highest value of the turbulence kinetic energy is found in the region just above the inlet stream and it is $6.5 e-5 \mathrm{~m}^{2} / \mathrm{s}^{2}$ per $\mathrm{kg}$ of the liquid. With a pair of baffles, the highest value is lowered to $5.0 e-5 \mathrm{~m}^{2} / \mathrm{s}^{2}$ per $\mathrm{kg}$ of the liquid (Figure 9(b)). For Case III as shown in Figure $9(\mathrm{c})$, the turbulence kinetic energy is greatly decreased and the highest value is $2.8 e-5 \mathrm{~m}^{2} / \mathrm{s}^{2}$ per $\mathrm{kg}$ of the liquid.

\section{Conclusions}

A numerical study was conducted to investigate the fluid flow and residence time distribution of the T-type two-strand continuous casting tundish with and without flow control devices. The following conclusions have been drawn from the present study.

(i) The application of a pair of baffles eliminates the short circuiting phenomena in the tundish and brings down the dead volume from $54 \%$ to $24 \%$. (ii) The employment of a TI and a pair of baffles is more effective to increase the plug fraction than a bare tundish or a tundish with just a pair of baffles, and it was found to be an optimum configuration of the two-strand tundish in the present study.

(iii) With a TI, the velocity vectors directed toward the tundish floor are smaller and the turbulence kinetic energy of the liquid steel top surface is lower than the other two arrangements, which means a more stable slag-metal interface.

\section{Acknowledgments}

This work was supported by the Natural Science Foundation of China (51210007) and the National Key Technology R\&D Program of China (2011BAK06B02).

\section{References}

[1] D. Mazumdar and R. I. L. Guthrie, "Physical and mathematical modelling of continuous casting tundish systems," ISIJ International, vol. 39, no. 6, pp. 524-547, 1999.

[2] L. Zhong, B. Li, Y. Zhu, R. Wang, W. Wang, and X. Zhang, "Fluid flow in a four-strand bloom continuous casting tundish with different flow modifiers," ISIJ International, vol. 47, no. 1, pp. 8894, 2007.

[3] A. Braun, M. Warzecha, and H. Pfeifer, "Numerical and physical modeling of steel flow in a two-strand tundish for different 
casting conditions," Metallurgical and Materials Transactions B, vol. 41, no. 3, pp. 549-559, 2010.

[4] T. Merder and J. Pieprzyca, "Numerical modeling of the influence subflux controller of turbulence on steel flow in the tundish," Metalurgija, vol. 50, no. 4, pp. 223-226, 2011.

[5] M. Warzecha and T. Merder, "Numerical analysis of the nonmetallic inclusions distribution and separation in a two-strand Tundish," Metalurgija, vol. 52, no. 2, pp. 153-156, 2013.

[6] R. D. Morales, J. J. de Barreto, S. López-Ramirez, J. PalafoxRamos, and D. Zacharias, "Melt flow control in a multistrand tundish using a turbulence inhibitor," Metallurgical and Materials Transactions B, vol. 31, no. 6, pp. 1505-1515, 2000.

[7] S. López-Ramirez, J. D. J. Barreto, J. Palafox-Ramos, R. D. Morales, and D. Zacharias, "Modeling study of the influence of turbulence inhibitors on the molten steel flow, tracer dispersion, and inclusion trajectories in tundishes," Metallurgical and Materials Transactions B, vol. 32, no. 4, pp. 615-627, 2001.

[8] B. Moumtez, A. Bellaouar, and K. Talbi, "Numerical investigation of the fluid flow in continuous casting Tundish using analysis of RTD curves," Journal of Iron and Steel Research International, vol. 16, no. 2, pp. 22-29, 2009.

[9] P. K. Jha and S. K. Dash, "Effect of outlet positions and various turbulence models on mixing in a single and multi strand tundish," International Journal of Numerical Methods for Heat and Fluid Flow, vol. 12, no. 5, pp. 560-584, 2002.

[10] A. Kumar, S. C. Koria, and D. Mazumdar, "An assessment of fluid flow modelling and residence time distribution phenomena in steelmaking tundish systems," ISIJ International, vol. 44, no. 8, pp. 1334-1341, 2004.

[11] T. Merder, "Effect of casting flow rate on steel flow phenomenna in Tundish," Metalurgija, vol. 52, no. 2, pp. 161-164, 2013.

[12] A. Kumar, D. Mazumdar, and S. C. Koria, "Experimental validation of flow and tracer-dispersion models in a four-strand billet-casting tundish," Metallurgical and Materials Transactions $B$, vol. 36, no. 6, pp. 777-785, 2005.

[13] K. J. Craig, D. J. de Kock, K. W. Makgata, and G. J. de Wet, "Design optimization of a single-strand continuous caster tundish using residence time distribution data," ISIJ International, vol. 41, no. 10, pp. 1194-1200, 2001.

[14] K. Chattopadhyay, M. Isac, and R. I. L. Guthrie, "Physical and mathematical modelling of steelmaking tundish operations: a review of the last decade (1999-2009)," ISIJ International, vol. 50, no. 3, pp. 331-348, 2010.

[15] B. E. Launder and D. B. Spalding, "The numerical computation of turbulent flows," Computer Methods in Applied Mechanics and Engineering, vol. 3, no. 2, pp. 269-289, 1974.

[16] S. V. Patankar, "Numerical heat transfer and fluid flow," McGraw-Hill, New York, NY, USA, 1980.

[17] H. Weller, G. Tabor, and H. C. Jasak, "Fureby A tensorial approach to computational continuum mechanics using objectoriented techniques," Computers in Physics, vol. 12, no. 6, pp. 620-631, 1998.

[18] S. Singh and S. C. Koria, "Model study of the dynamics of flow of steel melt in the tundish," ISIJ International, vol. 33, no. 12, pp. 1228-1237, 1993.

[19] J. Szekely and N. Themelis, Rate Phenomena in Process Metallurgy, Wiley Interscience, New York, NY, USA, 1972.

[20] Y. Sahai and T. Emi, "Melt flow characterization in continuous casting tundishes," ISIJ International, vol. 36, no. 6, pp. 667-672, 1996. 


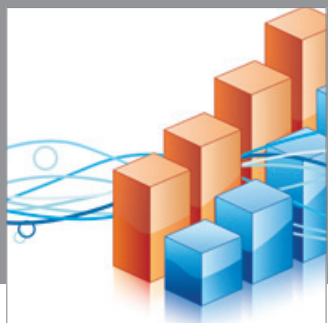

Advances in

Operations Research

mansans

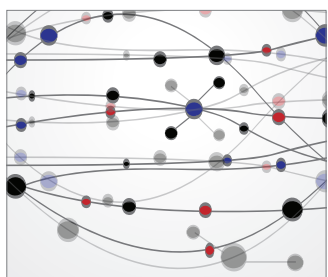

The Scientific World Journal
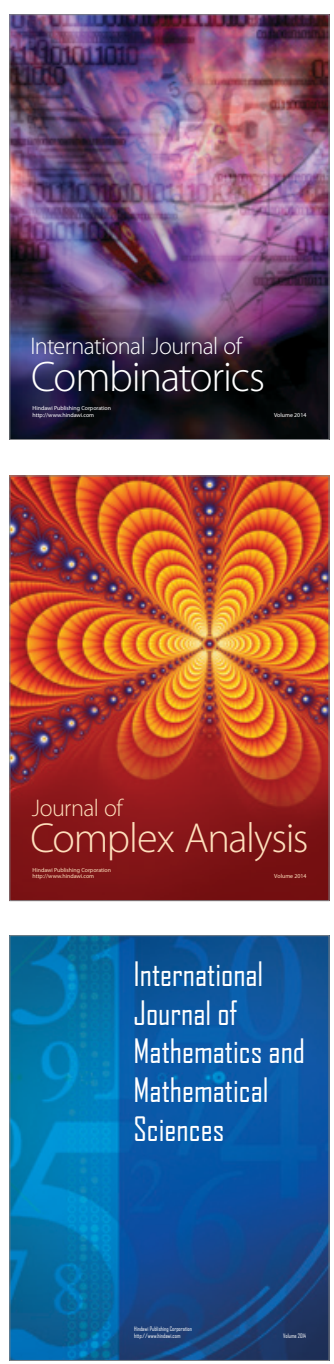
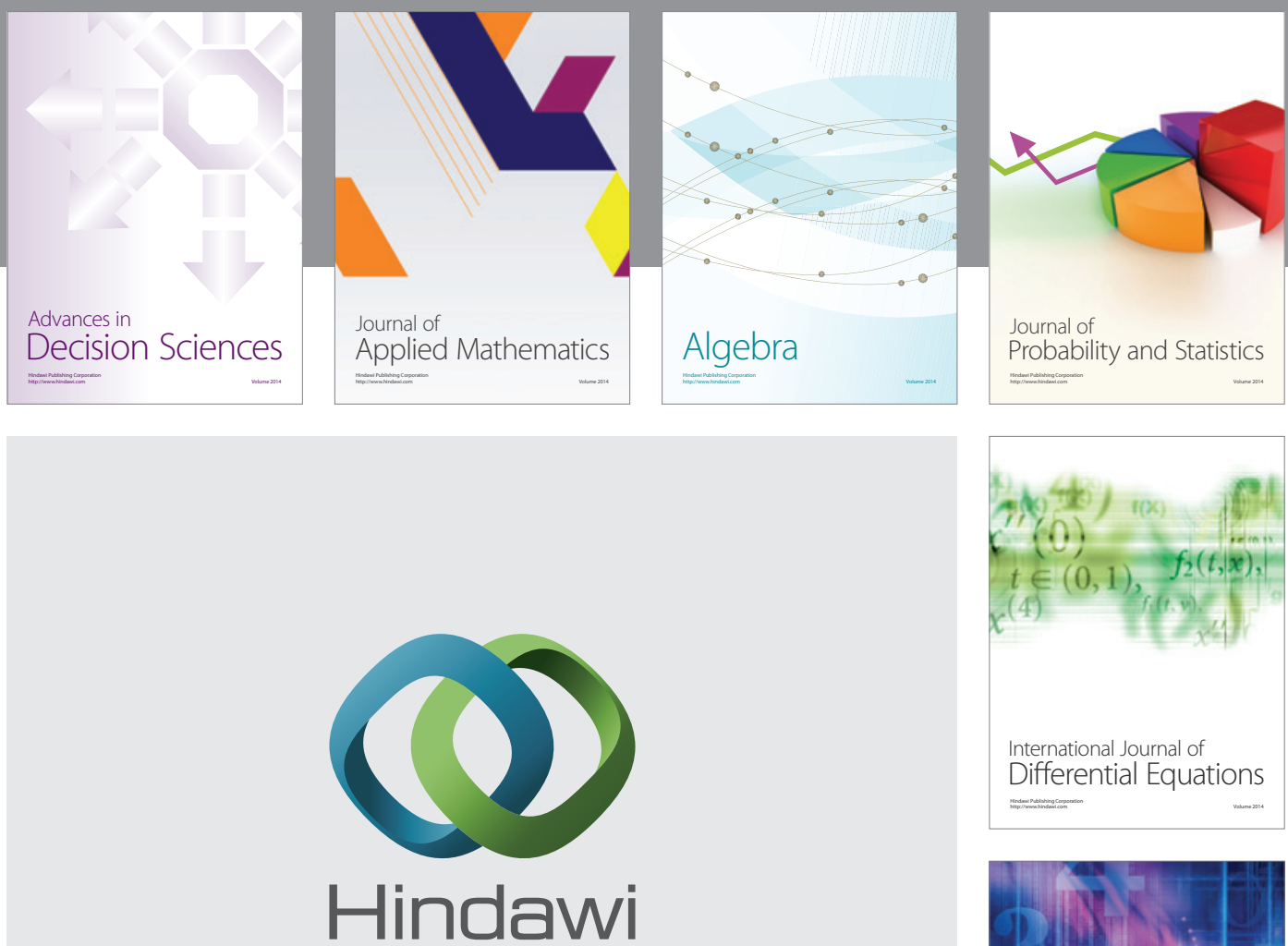

Submit your manuscripts at http://www.hindawi.com
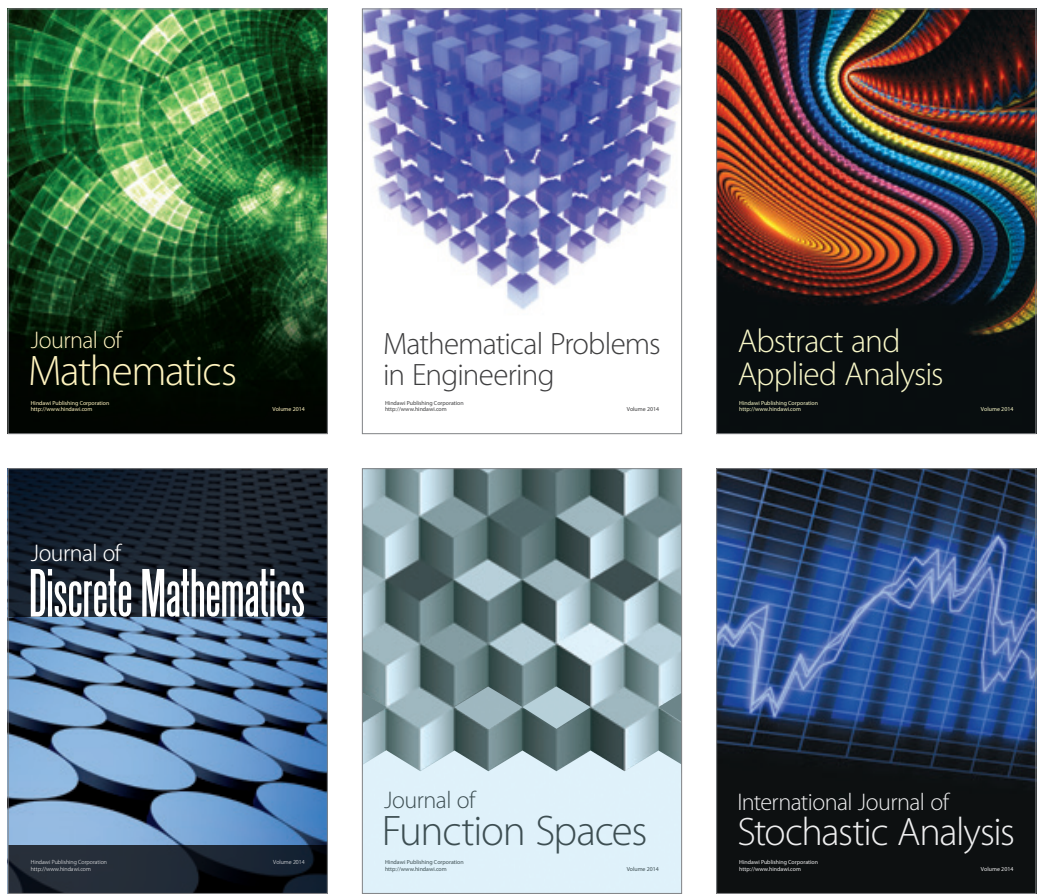

Journal of

Function Spaces

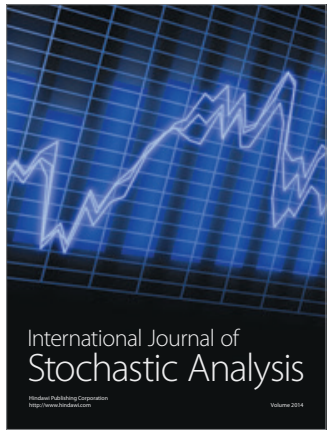

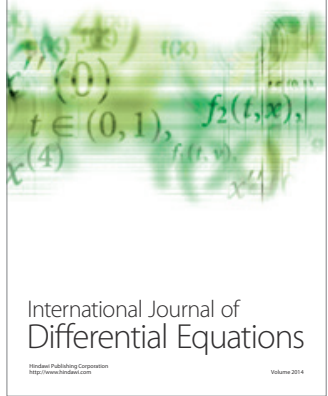
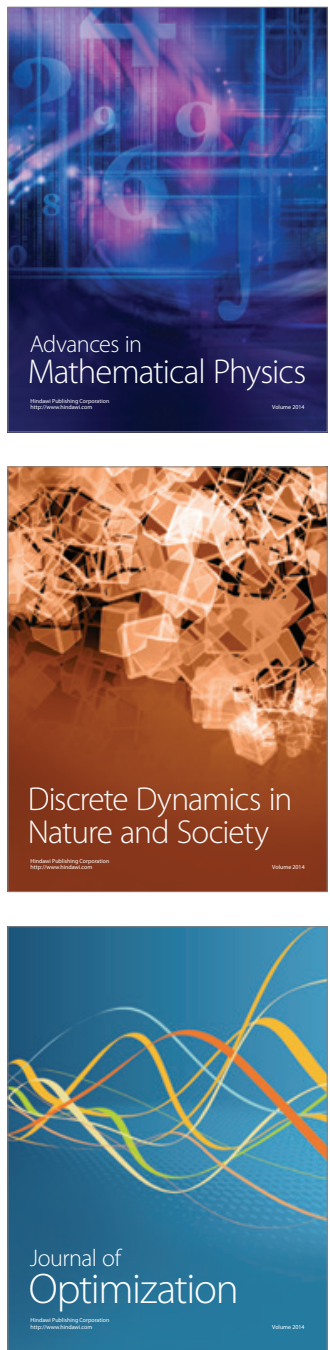